This item was submitted to Loughborough's Research Repository by the author.

Items in Figshare are protected by copyright, with all rights reserved, unless otherwise indicated.

\title{
Performance of Sn-3.0Ag-0.5Cu composite solder with TiC reinforcement: physical properties, solderability and microstructural evolution under isothermal ageing
}

\section{PLEASE CITE THE PUBLISHED VERSION}

http://dx.doi.org/10.1016/j.jallcom.2016.05.245

\section{PUBLISHER}

(C) Elsevier

\section{VERSION}

NA (Not Applicable or Unknown)

\section{PUBLISHER STATEMENT}

This work is made available according to the conditions of the Creative Commons Attribution-NonCommercialNoDerivatives 4.0 International (CC BY-NC-ND 4.0) licence. Full details of this licence are available at: https://creativecommons.org/licenses/by-nc-nd/4.0/

\section{LICENCE}

CC BY-NC-ND 4.0

\section{REPOSITORY RECORD}

Chen, Guang, Hao Peng, Vadim Silberschmidt, Y.C. Chan, Changqing Liu, and Fengshun Wu. 2016. "Performance of Sn-3.0ag-0.5cu Composite Solder with Tic Reinforcement: Physical Properties, Solderability and Microstructural Evolution Under Isothermal Ageing". Loughborough University. https://hdl.handle.net/2134/21917. 


\section{Performance of $\mathrm{Sn-3.0Ag-0.5Cu}$ composite solder with TiC reinforcement: physical properties, solderability and microstructural evolution under isothermal ageing}

Guang Chen ${ }^{1,2}$, Hao Peng ${ }^{1}$, Vadim V. Silberschmidt ${ }^{2}$, Y.C. Chan ${ }^{3}$, Changqing Liu $^{2 *}$ Fengshun $\mathrm{Wu}^{1^{*}}$

1 State Key Laboratory of Materials Processing and Die \& Mould Technology, Huazhong University of Science and Technology, Wuhan 430074, China 2 Wolfson School of Mechanical and Manufacturing Engineering, Loughborough University, $U K$

3 Department of Electronic Engineering, City University of Hong Kong, Tat Chee Avenue, KowLoon Tong, Hong Kong

${ }^{*}$ Corresponding authors: $1^{*}$ State Key Laboratory of Materials Processing and Die \& Mould Technology, Huazhong University of Science and Technology, Wuhan 430074, P.R. China, Tel: +86-27-87559182 , E-mail: fengshunwu@hust.edu.cn $2^{*}$ Wolfson School of Mechanical and Manufacturing Engineering, Loughborough University, UK, Tel: +44- 1509227681, E-mail: C.Liu@lboro.ac.uk

\section{Abstract}

This paper is focused on the effect of TiC nano-reinforcement that was successfully introduced into a SAC305 lead-free solder alloy with different weight fractions $(0,0.05,0.1$ and $0.2 \mathrm{wt} \%)$ through a powder-metallurgy route. Actual retained ratios of $\mathrm{TiC}$ reinforcement in composite solder billets and solder joints were 
quantitatively analysed. The obtained SAC/TiC solders were also studied extensively with regard to their coefficient of thermal expansion (CTE), wettability and thermal properties. In addition, evolution of interfacial intermetallic compounds (IMCs) and corresponding changes in mechanical properties under thermal ageing were investigated. Only about 10\%-30\% of initial TiC nanoparticles added were found retained in the final composite solder joints. With an appropriate addition amount of TiC nanoparticles, the composite solders exhibited an improvement in their wettability. A negligible change in their melting point and a widened melting range were found in composite solders containing TiC reinforcement. Also, the CTE of composite solder alloys was effectively decreased when compared with the plain SAC solder alloy. In addition, a growth of interfacial IMCs in composite solder joints was notably suppressed under isothermal ageing condition, while their corresponding mechanical properties of composite solder joints significantly outperformed those of non-reinforced solder joints throughout the ageing period.

Key words: TiC nanoparticles; Lead-free solder; Wettability; Interfacial IMC; Mechanical properties; Isothermal ageing

\section{Introduction}

Sn-Ag-Cu lead-free solders are now widely applied in the electronic packaging industry thanks to their excellent mechanical properties, good solderability and low environmental damage [1-3]. However, with a continuing trend of miniaturization and high integration in electronics, Sn-Ag-Cu solder joints are more frequently exposed to 
higher current density, larger joule heat and bigger thermal-mechanical stress. In such case, the SAC solder joints are increasingly threatened by reliability problems like thermal creep, electro-migration and thermo-migration. Thus, properties of Sn-Ag-Cu solders should be further improved to fulfil higher requirements resulted from the current needs of the electronics industry.

At present, introducing an appropriate amount of foreign particles into the matrix of a traditional solder alloy is regarded as a potentially feasible approach to improve the performance of the solder alloy. Up to now, many researchers have widely investigated the influence of different foreign reinforcements (such as metals, carbon-based materials and ceramics) on microstructural evolution as well as physical and mechanical properties of solder alloys [4-9]. From all the reinforcements studied, ceramic particles attracted more attention because of their relatively low cost and chemical stability. Fouzder et al. [10] reported that incorporation of $\mathrm{Al}_{2} \mathrm{O}_{3}$ nanoparticles showed a positive effect on microstructural refinement of a solder matrix and improvement of both microhardness and shear strength of solder joints. Through adoption of mechanical mixing, Tsao et al. [11] fabricated a $\mathrm{Sn}-0.7 \mathrm{Cu}$ nano-composite solder containing $\mathrm{TiO}_{2}$ nanoparticles. They found that a $\beta$-Sn phase and $\mathrm{Cu}_{6} \mathrm{Sn}_{5}$ IMCs were refined, while mechanical properties were improved compared to those of a eutectic Sn-0.7Cu solder. Shen et al. [12] incorporated $\mathrm{ZrO}_{2}$ nanoparticles into Sn-9Zn solder matrix and then studied microstructural evolution and mechanical properties of plain and composite Sn-9Zn solders joints. They reported that addition of $\mathrm{ZrO}_{2}$ nanoparticles to the solder joints significantly improved 
their reliability and shear strength after multiple reflows.

However, in comparison to other ceramic particles, widely recognized reinforcement in metal-matrix composites, TiC is rarely mentioned by researchers active in the research field of composite-solder. As we know, TiC is one typical metal carbide with excellent chemical stability and high melting temperature $\left(3067^{\circ} \mathrm{C}\right)$; it also exhibits good mechanical properties, with an elastic modulus of approximately $400 \mathrm{GPa}$ and a shear modulus of 188 GPa [13-15]. Additionally, relatively high electrical and thermal conductivity also make $\mathrm{TiC}$ a potential reinforcement for composite solders without affecting significantly their performance. To date, however, the influence of adding TiC nanoparticles on microstructural evolution, physical properties and solderability of Sn-Ag-Cu solder alloys has not been studied in detail yet. Thus, not only the retained ratio of $\mathrm{TiC}$ reinforcement added in SAC/TiC composite solder joints but also their physical properties and solderability are studied in this work. In addition, microstructural evolution of $\mathrm{Sn}-\mathrm{Ag}-\mathrm{Cu} / \mathrm{TiC}$ composite solder alloys together with the corresponding mechanical properties after different thermal ageing periods is also systematically investigated.

\section{Materials \& Experimental methods}

\subsection{Materials}

SAC305 (wt. \%) lead-free solder powder with an average particle diameter of $40 \mu \mathrm{m}$ was purchased from Suzhou EUNOW Electronic Materials (China). TiC nanoparticles (with diameter in the range of 20-40 nm) used as reinforcement in the 
present work were provided by XFNANO Materials Tech (China); their transmission electron microscope (TEM) images are shown in Fig. 1.

\subsection{Preparation of composite solders}

To prepare the composite solders for this study, TiC nanoparticles with different weight fractions $(0 \%, 0.05 \%, 0.10 \%$ and $0.20 \%)$, were homogeneously blended with the as-purchased SAC305 lead-free solder powder using a planetary ball mill for 20 hours at speed of $180 \mathrm{rpm}$. Specifically, to avoid impurities (especially, other metal elements) introduced by mixing, milling jars and balls made of super-hard zirconia were employed as the milling media. Then, the ball-milled solder powder was uniaxially compacted into cuboid solder billets (with dimension of $24 \mathrm{~mm} \times 8 \mathrm{~mm} \times 4$ mm) using a hydraulic compressor before being sintered in a vacuum oven with sintering temperature of $180^{\circ} \mathrm{C}$ for 3hrs. Finally, the sintered solder billets were rolled into solder foils with thickness of $200 \pm 20 \mu \mathrm{m}$ at room temperature $\left(\approx 20{ }^{\circ} \mathrm{C}\right)$. The as-sintered solder billets were directly subjected to CTE testing. For the convenience of wettability, melting behaviour, microstructural and mechanical analysis, these solder foils were further formed into solder balls $(800 \pm 10 \mu \mathrm{m}$ in diameter) in a reflow oven.

\subsection{Experimental procedures}

To precisely measure the retained ratio of $\mathrm{TiC}$ reinforcement added in the composite solder billets and final reflowed solder joints, the solder billets and joints 
(20 solder joints for each solder) were first ultrasonically dissolved in aqua regia before testing using an inductively coupled plasma optical emission spectroscopy (ICP-OES Varian-720) system with test precision at a ppm level. The retained ratios of $\mathrm{TiC}$ reinforcement were assessed based on an atomic weight fraction of Ti tested from in the aqua regia solutions.

The levels of CTE of the compacted solder billets after sintering were studied using a CTE analyzer (DIL 402C, NETZSCH, German) in the temperature range of $50-120^{\circ} \mathrm{C}$. The CTE value was obtained by calculating the linear length changes of solder billets at different temperature excursions; five samples were tested for each solder billet. Melting behaviours of both non-reinforced SAC solder and SAC/TiC composite solders were investigated using a differential scanning calorimeter (DSC). Specifically, the solder foils with their weight ranging from $5 \mathrm{mg}$ to $10 \mathrm{mg}$ were used as specimens for DSC tests; a heating rate during the tests was $10^{\circ} \mathrm{C} / \mathrm{min}$, and the highest heating temperature reached up to $250^{\circ} \mathrm{C}$. Wetting behaviour of SAC/TiC composite solders was investigated by means of measuring their wetting angles and spreading areas. During these tests, the solder balls with diameter of $800 \pm 10 \mu \mathrm{m}$ were placed on a polished copper substrate $(10 \mathrm{~mm} \times 10 \mathrm{~mm} \times 1.2 \mathrm{~mm})$ with no-clean flux. After a reflow process in a reflow oven at $245^{\circ} \mathrm{C}$, the contact angles of samples were subsequently measured using a camera in a contact-angle tester, while spreading areas of the solder joints were photographed by an environmental scanning electron microscope (ESEM-Quanta 200) system and then calculated with Image-J software.

For microstructural analysis, after etching in a 10 vol. $\% \mathrm{HNO}_{3}$ aqueous solution, 
top-view morphology of interfacial intermetallic compounds (IMCs) between the $\mathrm{Cu}$ substrate and the solder joint was observed using SEM. Further, to understand the reliability of the new SAC/TiC composite solders, isothermal ageing was also performed in this study. To implement the ageing test, plain and composite solder balls were first welded onto experimental Cu chips using a reflow oven. After that, all samples were placed in a vacuum oven with the ageing temperature of $150^{\circ} \mathrm{C}$ and ageing times of 0 h, 169 h, $324 \mathrm{~h}$ and $484 \mathrm{~h}$. Microstructural evolution of interfacial IMCs at the Cu/solder interface and mechanical properties (including microhardness and shear strength) of solder joints after different ageing times were systematically studied.

\section{Results and discussion}

\subsection{Retained ratio of TiC in solder joints}

To assess retained ratios of the TiC reinforcement in composite solder billets and solder joints, the TiC content was analyzed with ICP-OES; the respective results are presented in Figure 2. A reference line is incorporated in this figure, representing the ideal case with all nanoparticles remaining in the solder.

Apparently, the amount of TiC reinforcement in the solder billets and joints increases with the weight fraction of initial reinforcement added solder billets and joints. However, in both cases, the actual retained ratios of reinforcement show an obvious difference (especially, in solder joints) compared to the nominal composition. Specifically, for addition of $0.05,0.1$, and $0.2 \mathrm{wt}$ \% of TiC reinforcement into the 
SAC solder, the actual contents of TiC in the composite solder billets and solder joints were only $0.038,0.082,0.157$ and $0.016,0.018,0.019 \mathrm{wt}$. $\%$, respectively. These data clearly show that the added reinforcement was lost during the ball-milling and reflow processes. On the one hand, some part of reinforcement was not embedded into a surface of solder powder during the former process; it was left on surfaces of milling balls and milling jars, leading to a loss in the retained ratio of reinforcement (RROR) in the solder billets. In addition, evidently, the RROR was additionally diminished considerably during the reflow process: only a small fraction (approximately 10-30 wt. \%) of the total amount of TiC remained in the final solder joints. TiC, as a ceramic material, is difficult to wet reactively by the molten Sn-based solder during reflow process. As a result, relatively large interfacial tension between $\mathrm{TiC}$ and the molten solder could cause the exclusion of reinforcement from the solder joints, resulting in a further loss in RROR in solder joints.

\subsection{CTE}

The effects of foreign reinforcement on a magnitude of CTE of the composite solder alloys for a broad range of temperature was widely reported [16-17]. To understand thermal-expansion behaviour of composite solders, in the present work, the effect of TiC reinforcement on the instantaneous CTE of composite solders was studied. Evolution of CTE with temperature curves in the range from $50-120^{\circ} \mathrm{C}$ is presented in Fig. 3 for plain and composite solders. Apparently, the CTE values increased with increasing temperature for all the studied compositions, with the 
composite solders exhibiting lower CTEs than that of the SAC solder without reinforcement. In particular, the CTE of the composite colder with the highest fraction of reinforcement - SAC/0.2TiC - was some 8-10\% lower than that of the plain SAC throughout the whole studied temperature range. The obtained results illustrate that addition of TiC reinforcement facilitated improvement of dimensional stability of the composite solders in this temperature range. This phenomenon could be explained by a significantly lower CTE magnitude of $\mathrm{TiC}-7.4 \times 10^{-6} / \mathrm{K}$ - compared to that of the SAC solder alloy $-29.1 \times 10^{-6} / \mathrm{K}$ [18-19]. During heating, thermal expansion of the SAC solder matrix could be restricted by TiC reinforcement and effective bonding between it and the matrix.

\subsection{Thermal behaviour}

The melting point is a primary physical parameter to consider suitability of a solder alloy for applications in the electronic packaging industry. In this research, the melting point of different solders was identified using DSC curves. In general, the melting point is defined as the interaction of the extrapolated baseline and the tangent line of the maximum slope in the principle peak. The melting points of both plain and composite samples in this study are thus calculated in the range between $219.86^{\circ} \mathrm{C}$ and $220.08{ }^{\circ} \mathrm{C}$ (Fig. 4). These results indicate that the low weight fractions of $\mathrm{TiC}$ have a little effect on the melting point of the solder alloy. It was proposed by Lindemann [20] that the melting point of a material is an inherent physical property, which is mainly determined by the inter-atomic distance and the atomic mean-square 
191

192

193

displacements. In this study, the balance between these parameters in the solder alloy can hardly be broken through adding a small amount of TiC nanoparticles; thus, the influence of TiC reinforcement on its melting point would be very limited. However, after calculating the difference between the onset and end of melting for all the samples, it was found that the melting range of solder alloys exhibits an upward trend with a growing amount of TiC particles. This range is listed in Table 1 for different solders; apparently, the melting range for $\mathrm{SAC} / 0.2 \mathrm{TiC}$ solder is $4.97^{\circ} \mathrm{C}, 28.8 \%$ higher than that for the plain SAC solder. The reason for this phenomenon is concluded to be the difference in thermal conductivities of TiC $(16.7 \mathrm{~W} / \mathrm{m} \mathrm{K})$ and SAC solder (50 $\mathrm{W} / \mathrm{m} \mathrm{K}$ ); lower thermal conductivity of reinforcement might reduce total thermal conductivity of $\mathrm{SAC} / \mathrm{TiC}$ composite solder and cause the increase in its melting range. Thus, to improve solderability and applicability of SAC/TiC composite solders, an optimal addition amount of TiC needs to be further studied.

\subsection{Wettability}

Building a reliable bonding between a substrate and a solder joint is critically important for electronic packaging. The quality of such solder bonding is largely determined by wettability of the solder alloy [21]. In general, solder alloys with larger spreading areas angles and smaller contact also tend to offer more reliable interconnections during a reflow process. Thus, in this section, wettability of the newly prepared SAC/TiC composite solders was investigated by testing their spreading areas and contact angles on the polished $\mathrm{Cu}$ substrate; relevant results are 
presented in Fig. 5.

It was found that the contact angles of solders decreased firstly and then increased with the increasing content of TiC (Fig. 5), with the data for the spreading area showing an opposite trend. Specifically, the contact angle firstly decreased - from $34.7^{\circ}$ for the non-reinforced SAC to $30.3^{\circ}$ for the composite solder with $0.1 \mathrm{wt} . \% \mathrm{TiC}$ reinforcement, followed by an upward trend, with the contact angle increasing to $33.8^{\circ}$ for 0.2 wt.\% of $\mathrm{TiC}$. Correspondingly, the spreading area of the composite solder reached the maximum value $-2.168 \mathrm{~mm}^{2}$ when the content of $\mathrm{TiC}$ nanoparticles was 0.1 wt.\%, which is $10.8 \%$ larger than that of plain SAC solder. However, it decreased to $1.995 \mathrm{~mm}^{2}$ for $0.2 \mathrm{wt} \%$ of nano-reinforcement. These results indicate that the relatively small addition of $\mathrm{TiC}$ nanoparticles into solder matrix contributes to improve wettability of the composite solder alloys. The possible reason for this phenomenon is that the appropriate TiC nanoparticles doped tend to accumulate at the interface between the flux and the molten solder during reflowing, lowering the interfacial surface energy and leading to reduced interfacial tension between them, forming eventually a smaller contact angle. Nevertheless, the excess of TiC reinforcement might increases viscosity of the molten solder, hindering its spreading. Additionally, higher fractions of TiC nanoparticles may result in their aggregation at the solder/flux interface, increasing the interfacial tension and thus leading to the decrease in wettability. 


\subsection{Microstructural analysis}

To understand the effect of $\mathrm{TiC}$ reinforcement on morphology of interfacial IMCs between the solder and the $\mathrm{Cu}$ substrate, the top-view SEM images of interfacial IMCs were obtained in this study. Typical SEM images of plain SAC and SAC containing 0.2 wt.\% TiC reinforcement are presented in Fig. 6. Apparently, morphology of interfacial IMCs, namely $\mathrm{Cu}_{6} \mathrm{Sn}_{5}$, exhibited obvious changes after TiC addition, from circular granular to interlaced short rods. In addition to this, grain sizes of these interfacial IMCs also show a difference: an average diameter of interfacial $\mathrm{Cu}_{6} \mathrm{Sn}_{5}$ grains ( $\mathrm{d}_{1}$ in Fig. 6c) in the $\mathrm{SAC} / \mathrm{Cu}$ system is $1.75 \pm 0.3 \mu \mathrm{m}$, while the counterpart data ( $\mathrm{d}_{2}$ in Fig. $6 \mathrm{~d}$ ) for $\mathrm{SAC} / 0.2 \mathrm{TiC} / \mathrm{Cu}$ is $0.72 \pm 0.2 \mu \mathrm{m}$. Besides, some strip-like $\mathrm{Cu}_{6} \mathrm{Sn}_{5}$ IMCs with a larger size were found formed above the interfacial IMC layer (Fig. 6b).

These transformations in morphology and the grain size of the interfacial IMCs were defined by reaction kinetics; a schematic of $\mathrm{Cu}$ and $\mathrm{Sn}$ fluxes at the solder/Cu interface are shown in Fig. 7. For the SAC/Cu system, fluxes of $\mathrm{Cu}$ and $\mathrm{Sn}$ atoms, coming from the $\mathrm{Cu}$ substrate and the molten solder, respectively, met directly at the $\mathrm{Cu}$ /solder interface, forming interfacial common $\mathrm{Cu}_{6} \mathrm{Sn}_{5}$-scallop-like or circular granular. However, the diffusional direction and the interfacial atomic concentration of $\mathrm{Cu}$ and $\mathrm{Sn}$ atoms in the $\mathrm{SAC} / \mathrm{TiC} / \mathrm{Cu}$ system might be influenced by $\mathrm{TiC}$ reinforcement. Specifically, as discussed in Section 3.1, TiC would be expelled out of a solder joint during the reflow process. As shown in Fig.7, the expelled TiC nanoparticles tend to accumulate at the solder/Cu interface, regarded as a main path 
for $\mathrm{TiC}$ exclusion. In such case, the initial diffusional equilibrium for $\mathrm{Sn}$ and $\mathrm{Cu}$ atoms would be broken due to the presence of $\mathrm{TiC}$ particles, leading to variation in crystallization conditions of interfacial IMCs and resulting in new $\mathrm{Cu}_{6} \mathrm{Sn}_{5}$ with different morphology. As for the formation of strip-like $\mathrm{Cu}_{6} \mathrm{Sn}_{5}$, non-equilibrium diffusion of $\mathrm{Cu}$ atoms and thermal behaviour of the composite solder could give an explanation. On the one hand, the distribution of expelled $\mathrm{TiC}$ at the $\mathrm{Cu} /$ solder interface was not homogeneous, which might generate different diffusion paths (with different diffusional speeds) for $\mathrm{Cu}$ atoms. Additionally, the melting range (mentioned in Section 3.3) of the solder alloy was widened after TiC addition, providing an additional time for $\mathrm{Cu}$ diffusion. So, some $\mathrm{Cu}$ atoms were more likely to use a path with lower reinforcement and reach inner areas of the molten solder, forming strip-like $\mathrm{Cu}_{6} \mathrm{Sn}_{5}$ with a larger size.

To further understand microstructural evolution of interfacial IMCs, the plain and composite solder samples were subjected to isothermal ageing. The resulting morphologies of interfacial IMCs are shown Fig. 8 for all the samples before and after thermal ageing. It can be seen that the interfacial IMCs of the as-reflowed (0 h) SAC solder show a common scallop-like morphology, while a "porous" interface was found in all as-reflowed $(0 \mathrm{~h})$ composite solders; the degree of porosity was directly proportional to the fraction of TiC reinforcement. Based on the above analysis on the morphology of interfacial IMCs, it can be concluded that the so-called "porous" morphology is actually a cross-sectional appearance of an interlaced short-rod structure. Further, by studying line-scanning EDS results (Fig.9a), it could be 
concluded that the "porous" area is filled with TiC reinforcement, resulting from it exclusion during the reflow process. With increase in the ageing time, thickness of interfacial IMCs (including $\mathrm{Cu}_{6} \mathrm{Sn}_{5}$ and $\mathrm{Cu}_{3} \mathrm{Sn}$ ) for all samples showed a continuous growth, while they became more flat in all the solder samples. In addition, the "porous" interface (especially in SAC/0.2TiC) became more compacted, with "pores" gradually moving to the top of IMC; their size diminished continuously. According to the EDS results (Fig.9b), the TiC reinforcement was still present at the smaller "pores" and the top interface between the IMCs and the solder matrix. This phenomenon indicates that part of the initially non-expelled TiC reinforcement remained near the interfacial IMC layer, although their location could change due to the growth of IMC. Additionally, to study precisely the growth rate of interfacial IMCs, the thickness data for $\mathrm{Cu}_{6} \mathrm{Sn}_{5}$ and $\mathrm{Cu}_{3} \mathrm{Sn}$ for all the samples was acquired after different ageing times using software Image $\mathrm{J}$ (Fig. 10). Herein, it is necessary to point out that the "porous area" (black dots in Fig. 9) existed in interfacial IMCs was excluded when IMC thickness of the composite solders was calculated in order to obtain the real thickness data. It is evident that interfacial IMCs (in particular, $\mathrm{Cu}_{3} \mathrm{Sn}$ ) showed a considerable growth in the non-reinforced SAC solder: thickness magnitudes for $\mathrm{Cu}_{6} \mathrm{Sn}_{5}$ and $\mathrm{Cu}_{3} \mathrm{Sn}$ after $484 \mathrm{~h}$ ageing were $9.32 \pm 0.24 \mu \mathrm{m}$ and $3.4 \pm 0.12 \mu \mathrm{m}$, respectively, 1.2 and 8.4 times thicker than those before isothermal ageing. As for the composite solders, although the $\mathrm{Cu}_{6} \mathrm{Sn}_{5}$ layers exhibited a similar increasing trend, a lower growth rate was found throughout the ageing process. Specifically, the changes in thickness for $\mathrm{Cu}_{6} \mathrm{Sn}_{5}$ for SAC/0.05TiC, SAC/0.1TiC and SAC/0.2TiC after $484 \mathrm{~h}$ 
ageing were only $69.4 \%, 22.5 \%$ and $5.8 \%$, respectively, far less than those for the non-reinforced SAC solder. Unlike the considerable growth of $\mathrm{Cu}_{3} \mathrm{Sn}$ in latter during the ageing period, the growth of $\mathrm{Cu}_{3} \mathrm{Sn}$ in the composite solder with $\mathrm{TiC}$ reinforcement was supressed to a great extent (Fig. 10b). Among all three studied composite solders, the growth rate for $\mathrm{Cu}_{3} \mathrm{Sn}$ in $\mathrm{SAC} / 0.1 \mathrm{TiC}$ was found to be the lowest. Thickness of $\mathrm{Cu}_{3} \mathrm{Sn}$ in the aged SAC/0.1TiC solder was only about 1.06 times thicker than the initial value, which is much thinner than that for its non-reinforced counterpart. The supressed growth rate of $\mathrm{Cu}_{6} \mathrm{Sn}_{5}$ and $\mathrm{Cu}_{3} \mathrm{Sn}$ can be explained by the effect of $\mathrm{TiC}$ at the $\mathrm{Cu}$ /solder interface on diffusion. On the one hand, as proposed by other researchers in previous studies [22-23], the expelled reinforcements are more like to adsorb on the surface of interfacial IMCs $\left(\mathrm{Cu}_{6} \mathrm{Sn}_{5}\right.$ is the most possible in this study), retarding a further growth of IMCs through hindering diffusion. On the other hand, the enrichment of reinforcement could also decreases a concentration gradient of Sn atoms at the interface and, thus, lower the growth of interfacial IMC (especially, for $\mathrm{Cu}_{3} \mathrm{Sn}$ ). In addition, it is worth noting that a slightly larger thickness of $\mathrm{Cu}_{3} \mathrm{Sn}$ was observed in the aged SAC/0.2TiC solder joint, compared with SAC/0.05TiC and SAC/0.1TiC solder joints. This phenomenon could be attributed to a possible increase in interfacial temperature. As well known, thermal conductivity of TiC and SAC solder alloy are $50 \mathrm{~W} / \mathrm{m} \mathrm{K}$ and $16.7 \mathrm{~W} / \mathrm{m} \mathrm{K}$, respectively. If there is a relatively high quantity of $\mathrm{TiC}$ reinforcements at the $\mathrm{Cu} /$ solder interface, the level of its thermal conductivity would be decreased to some extent. In such a case, the interfacial temperature would be elevated and, in turn, accelerate the diffusion process of Sn 
atom, from inner areas of the solder to the interface.

In addition, to quantitatively study the effect of $\mathrm{TiC}$ reinforcement on microstructural evolution of interfacial IMCs $\left(\mathrm{Cu}_{6} \mathrm{Sn}_{5}+\mathrm{Cu}_{3} \mathrm{Sn}\right)$, a diffusion coefficient of different solder alloys under thermal ageing $\left(150^{\circ} \mathrm{C}\right)$ were also calculated employing an empirical diffusion formula as follows:

$$
X_{t}=X_{0}+\sqrt{D t}
$$

where $X_{t}$ is the overall IMC thickness (in $\mathrm{m}$ ) at the ageing time $t$ (in s), $X_{0}$ is the initial thickness after one reflowing, and $D$ is the diffusion coefficient (in $\mathrm{m}^{2} / \mathrm{s}$ ). From Eq. (1) and the data presented in Fig. 10a, the diffusion coefficients of SAC, SAC/0.05TiC, SAC/0.1TiC and SAC/0.2TiC were calculated to be 14.9277, 5.5511, 1.0305 and $0.3042\left(\times 10^{-18} \mathrm{~m}^{2} / \mathrm{s}\right)$, respectively. This result could also explain the suppressed growth of interfacial IMCs after TiC addition.

\subsection{Mechanical properties}

Mechanical properties (including shear strength and microhardness) of the studied solder alloys exposed to ageing of different durations were also studied; the results of mechanical testing are presented in Figs. 11 and 12 together with typical microstructures of the solder matrix. Shear test results (Fig.11a) demonstrate that initial shear strength (before thermal ageing) of the composite solders containing relatively small amounts of $\mathrm{TiC}$ is similar $(\approx 48.5 \mathrm{MPa})$ to that of the non-reinforced solder. However, the composite solder with a higher content of reinforcement (0.2wt.\% TiC) exhibited lower shear strength (approximately, 46.8 MPa) compared to that of 
341

the non-reinforced counterpart. This phenomenon could be explained by different interfacial microstructures (Fig. 8). Before ageing (as-reflowed condition), although the morphologies of interfacial IMCs were slightly different, their thickness data are relatively close. Thus, such interfacial IMCs with similar thickness determined a similar response in the shear test. However, when the fraction of reinforcement is relatively high, morphology of interfacial IMCs was significantly different: its thickness increased considerably and they seemed more "porous" (as discussed above); thicker interfacial IMCs and the "porous" structure might directly result in a decrease in shear strength. Still, as the ageing time increased, although all of samples showed a downward trend in shear strength, its decline rate for the non-reinforced solder joint was much higher than that for composite joints. After $484 \mathrm{~h}$ ageing, the average shear strength levels for SAC/0.05TiC, SAC/0.1TiC and SAC/0.2TiC were 44.1 MPa 45.8 MPa and 44.7 MPa, respectively; all of these tested data for composite solder joints were markedly higher than that for the plain SAC joint(38.2 MPa). The enhancement in shear strength of composite solder joints are mainly attributable to the significantly supressed growth of $\mathrm{Cu}_{3} \mathrm{Sn}$ in the composite solder joints. According to previous studies, Kirkendall voids are more likely formed in a $\mathrm{Cu}_{3} \mathrm{Sn}$ layer because of different diffusional rates of metal atoms [24]. A thinner Cu3Sn layer could help to retard formation and growth of Kirkendall voids. In this study, it could be found in Fig. 8 that Kirkendall voids formed in the Cu3Sn IMC layer in the plain SAC solder after $324 \mathrm{~h}$ ageing and their numbers further increased after $484 \mathrm{~h}$; it is regarded as a main factor causing the decrease in shear strength. In contrast, there were nearly no 
363

364

Kirkendall voids formed at interfacial IMCs in the aged composite solder joints. Therefore, such a more reliable interface with no Kirkendall voids determined their better shear strength.

In addition to shear strength, the microhardness magnitudes for all the composite samples were apparently higher than that of the non-reinforced solder throughout the whole ageing period. Unlike the shear-strength results, the levels of microhardness for different composites increased with the weight fraction of TiC reinforcement. Specifically, the microhardness of SAC, SAC/0.05TiC, SAC/0.1TiC and SAC/0.2TiC were $13.14 \mathrm{HV}, 14.06 \mathrm{HV}, 14.39 \mathrm{HV}$ and $14.42 \mathrm{HV}$ before ageing, while the corresponding data for these solders after $484 \mathrm{~h}$ ageing were $11.86 \mathrm{HV}, 12.93 \mathrm{HV}$, $13.39 \mathrm{HV}$ and $13.52 \mathrm{HV}$, respectively. So, the testing data demonstrate that microhardness of the studied composite solder joints was approximately $10 \%$ higher than that of the non-reinforced one. Here, a theory of dispersion strengthening could give an explanation for the observed enhancement of microhardness in composite solders [25]. Accordingly to the theory, the presence of reinforcements added in grain boundaries and solder matrices are likely to affect the deformation characteristics of solder alloys by retarding dislocation movement and impeding grain-boundary sliding in solder matrices, resulting in improvement in micro-hardness. In addition, the improvement in microhardness of composite solder joints (especially, after ageing) can also be explained in terms of microstructural evolution. Apparently coarsened Ag3Sn IMCs were observed in the non-reinforced SAC solder after $484 \mathrm{~h}$ ageing compared with the microstructure of the as-reflowed sample (Figs. 12a and b). As for 
385

386

387

the SAC/0.2TiC composite solder (see Figs. 12c and d), although $\mathrm{Ag}_{3} \mathrm{Sn}$ IMCs also coarsened after thermal ageing, their size was obviously smaller than that of the non-reinforced solder. The lower growth of $\mathrm{Ag}_{3} \mathrm{Sn}$ IMCs might be attributed to adsorption of $\mathrm{TiC}$ on the surface of $\mathrm{Ag}_{3} \mathrm{Sn}$ IMC during the reflow process, which could, in turn, decrease diffusion during ageing, leading eventually to a finer microstructure. Since microstructure of an alloy has a crucial effect on its microhardness, refined Ag3Sn IMCs and the accompanying dispersion-strengthening effect can thus explain the improvement of microhardness in the studied SAC/TiC composite solders.

\section{Conclusion}

SAC305 composite solders reinforced with different fractions of TiC nanoparticles were prepared using a powder metallurgic method. In addition to their physical properties and solderability, microstructural evolution of interfacial IMCs and relevant mechanical properties caused by isothermal ageing of different durations were also systematically studied. Main experimental results of the undertaken research are as follows:

1) The presence of $\mathrm{TiC}$ reinforcement in the $\mathrm{SAC} / \mathrm{TiC}$ composite solder matrix was confirmed with ICP-OES; in addition, the actual retained ratios of TiC particles in both composite solder billets and joints showed a decline due to their loss in the ball-mill process and expulsion from the molten solder during the reflow process. 
405

406

407

408

409

410

411

412

413

414

415

416

417

418

419

420

421

422

423

424

425

2) The TiC reinforced composite solders were found have lower CTE values compared with the non-reinforced SAC solders, indicating their higher dimensional stability than that of the non-reinforced solder.

3) Negligible changes in the melting point of the composite solders were observed together with wider melting ranges. The wettability results showed its improvement with incorporation of TiC nanoparticles into the solder matrix.

4) Morphology of interfacial $\mathrm{Cu}_{6} \mathrm{Sn}_{5}$ was transformed from circular granular to short-rod-like with TiC addition, while the supressed growth rate of interfacial IMCs was observed in the composite solders during isothermal ageing. In addition, formation of Kirkendall voids in the interfacial Cu3Sn IMC was retarded to a large extent.

5) Mechanical testing results indicated that the appropriate doping of $\mathrm{TiC}$ nanoparticles to the solder matrix can lead to an improvement in both shear strength and microhardness of the composite solders.

\section{Acknowledgement}

The authors acknowledge the research funding by the National Nature Science Foundation of China (NSFC) and The Research Grants Council (RGC) Joint Research project (NSFC NO. 61261160498, RGC NO.CityU101/12). This research was also supported by the China-European Union technology cooperation project, No. 1110 as well as the Marie Curie International Research Staff Exchange Scheme Project within the $7^{\text {th }}$ European Community Framework Programme, No. PIRSES-GA-2010-269113, 
entitled “Micro-Multi-Material Manufacture to Enable Multifunctional Miniaturised Devices (M6)”. The authors are also grateful to the State Key Laboratory of Materials

Processing and Die \& Mould Technology and the Analytical and Testing Centre in Huazhong University of Science Technology for their analytical and testing services.

\section{Reference}

[1] E.M.N. Ervina, S. Amares, T.C. Yap, A review: influence of nanoparticles reinforced on solder alloy, Solder Surf Mt Tech, 25 (4) (2013) 229-241.

[2] X. Hu, W. Chen, B. Wu, Microstructure and tensile properties of Sn-1Cu lead-free solder alloy produced by directional solidification, Mater Sci Eng A, 556 (2012) 816-823.

[3] B. Wang, J. Li, A. Gallagher, J. Wrezel, P. Towashirporn, N. Zhao, Drop impact reliability of Sn-1.0Ag-0.5Cu BGA interconnects with different mounting methods, Microelectron Reliab, 52 (2012) 1475-1482.

[4] L.L. Gao, S.B. Xue, L. Zhang, Z. Sheng, F. Ji, W. Dai, S.L. Yu, G. Zeng, Effect of alloying elements on properties and microstructures of $\mathrm{SnAgCu}$ solders, Microelectron Eng, 87 (2010) 2025-2034.

[5] G. Chen, F.S. Wu, C. Liu, V. Silberschmidt, Y.C. Chan, Microstructures and properties of new Sn-Ag-Cu lead-free solder reinforced with Ni-coated graphene nanosheets, J Alloy Compd, 656 (2016) 500-509.

[6] L.Y. Xu, L.X. Wang, H.Y. Jing, X.D. Liu, J. Wei, Y.D. Han, Effects of graphene nanosheets on interfacial reaction of SneAgeCu solder joints, J Alloy Compd, 650 (2015) 475-481.

[7] M. Sobhy, A.M. El-Refai, M.M. Mousa, G. Saad, Effect of ageing time on the tensile behavior of Sn-3.5 wt\% Ag-0.5 wt\% Cu (SAC355) solder alloy with and without adding ZnO nanoparticles, Mater Sci Eng A, 646 (2015) 82-89. 
[8] S. Chellvarajoo, M.Z. Abdullah, Z. Samsudin, Effects of $\mathrm{Fe}_{2} \mathrm{NiO}_{4}$ nanoparticles

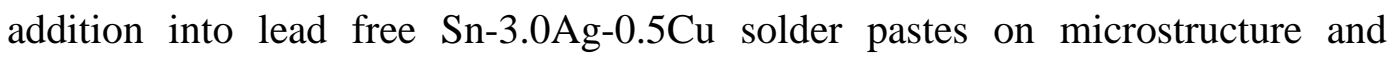
mechanical properties after reflow soldering process, Mater Design, 67 (2015) 197-208.

[9] A.A. El-Daly, W.M. Desoky, T.A. Elmosalami, M.G. El-Shaarawy, A.M. Abdraboh, Microstructural modifications and properties of SiC nanoparticles-reinforced Sn-3.0Ag-0.5Cu solder alloy, Mater Design, 65 (2015) 1196-1204.

[10] T. Fouzder, A. K. Gain, Y.C. Chan, A. Sharif, Winco K.C. Yung, Effect of nano $\mathrm{Al}_{2} \mathrm{O}_{3}$ additions on the microstructure, hardness and shear strength of eutectic Sn-9Zn solder on Au/Ni metallized Cu pads, Microelectron Reliab, 50 (2010) 2051-2058.

[11] L.C. Tsao, C.H. Huang, C.H. Chung, R.S. Chen, Influence of $\mathrm{TiO}_{2}$ nanoparticles addition on the microstructural and mechanical properties of $\mathrm{Sn} 0.7 \mathrm{Cu}$ nano-composite solder, Mater Sci Eng A, 545 (2012) 194-200.

[12] J. Shen, Y.C. Chan, Effects of $\mathrm{ZrO}_{2}$ nanoparticles on the mechanical properties of Sn-Zn solder joints on Au/Ni/Cu pads, J Alloy Compd, 477 (2009) 552-559.

[13] E.K. Stroms, The Refractory Carbides, Refractory Materials Series, vol. 2, Academic Press, New York, 1967.

[14] L.E. Toth, Transition Metal Carbides and Nitrides, Academic Press, New York, 1971.

[15] H.O. Pierson, Handbook of Refractory Carbides and Nitrides, Noyes Publications, Westwood, 1996.

[16] K. Mohan-Kumar, V. Kripesh, A.A.O. Tay, Influence of single-wall carbon nanotube addition on the microstructural and tensile properties of $\mathrm{Sn}-\mathrm{Pb}$ solder alloy, J. Alloys Compd, 455 (2008)148-158.

[17] Z.X. Li, M. Gupta, High strength lead-free composite solder materials using nano $\mathrm{Al}_{2} \mathrm{O}_{3}$ as reinforcement, Adv Eng Mater, 11 (2005) 1049-1054.

[18] X.C. Li, J. Stampfl, F. B. Prinz, Mechanical and thermal expansion behavior of laser deposited metal matrix composites of Invar and TiC, Mater Sci Eng A, 282 
(2000) 86-90.

482

483

484

485

486

487

488

489

490

491

492

493

494

495

496

[19] X.D. Liu, Y.D. Han, H.Y. Jing, J. Wei, L.Y. Xu, Effect of graphene nanosheets reinforcement on the performance of Sn-Ag-Cu lead-free solder, Mater Sci Eng A, 562 (2013) 25-32.

[20] F. Lindemann, Physik. Zeitschr., 11 (1910) 609-615.

[21] K.N. Tu, K. Zeng, Tin-lead ( $\mathrm{SnPb}$ ) solder reaction in flip ship technology, Mater Sci Eng R, 34 (2001) 1-58.

[22] L.C. Tsao, Suppressing effect of 0.5 wt.\% nano- $\mathrm{TiO}_{2}$ addition into Sn-3.5Ag-0.5Cu solder alloy on the intermetallic growth with $\mathrm{Cu}$ substrate during isothermal aging, J. Alloys Compd, 509 (2011) 8441-8448.

[23] A.S.M.A. Haseeb, M.M. Arafat, M. R. Johan, Stability of molybdenum nanoparticles in Sn-3.8Ag-0.7Cu solder during multiple reflow and their influence on interfacial intermetallic compounds, Mater Charact, 64 (2012) 27-35.

[24] L. Yin, P. Borgesen, On the root cause of Kirkendall voiding in $\mathrm{Cu}_{3} \mathrm{Sn}$, J. Mater. Res, 26 (2011) 455-466.[25] J.W. Martin, Precipitation hardening, Butterworth Heinemann, Oxford, UK, 1998. 

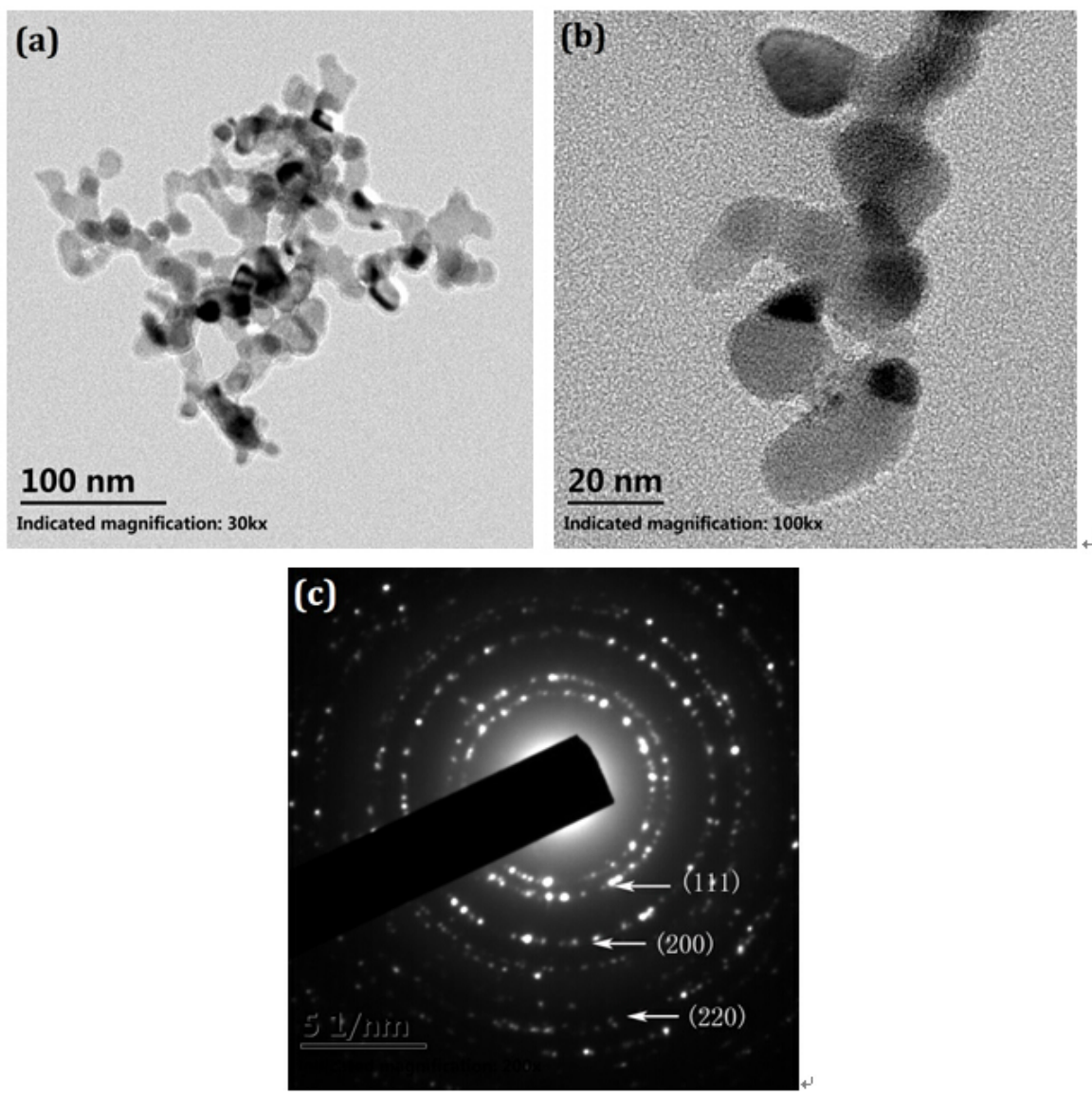

Fig. 1 TEM images of the original TiC nanoparticles: (a) and (b) bright-field images: (c) selected area diffraction pattern 


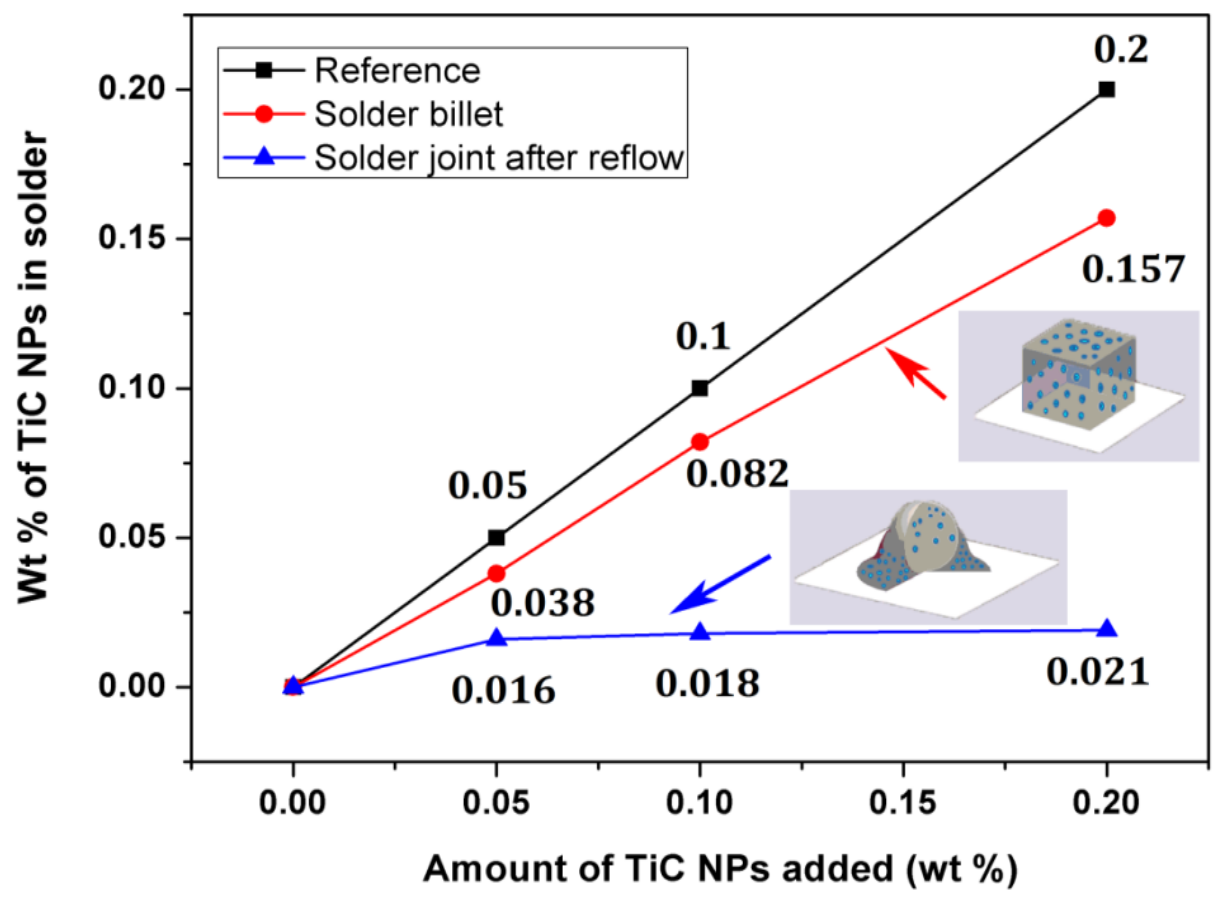

Fig. 2 Retained ratios of TiC reinforcement in solder billets and solder joints after reflow as function of nominal weight fraction of TiC added 


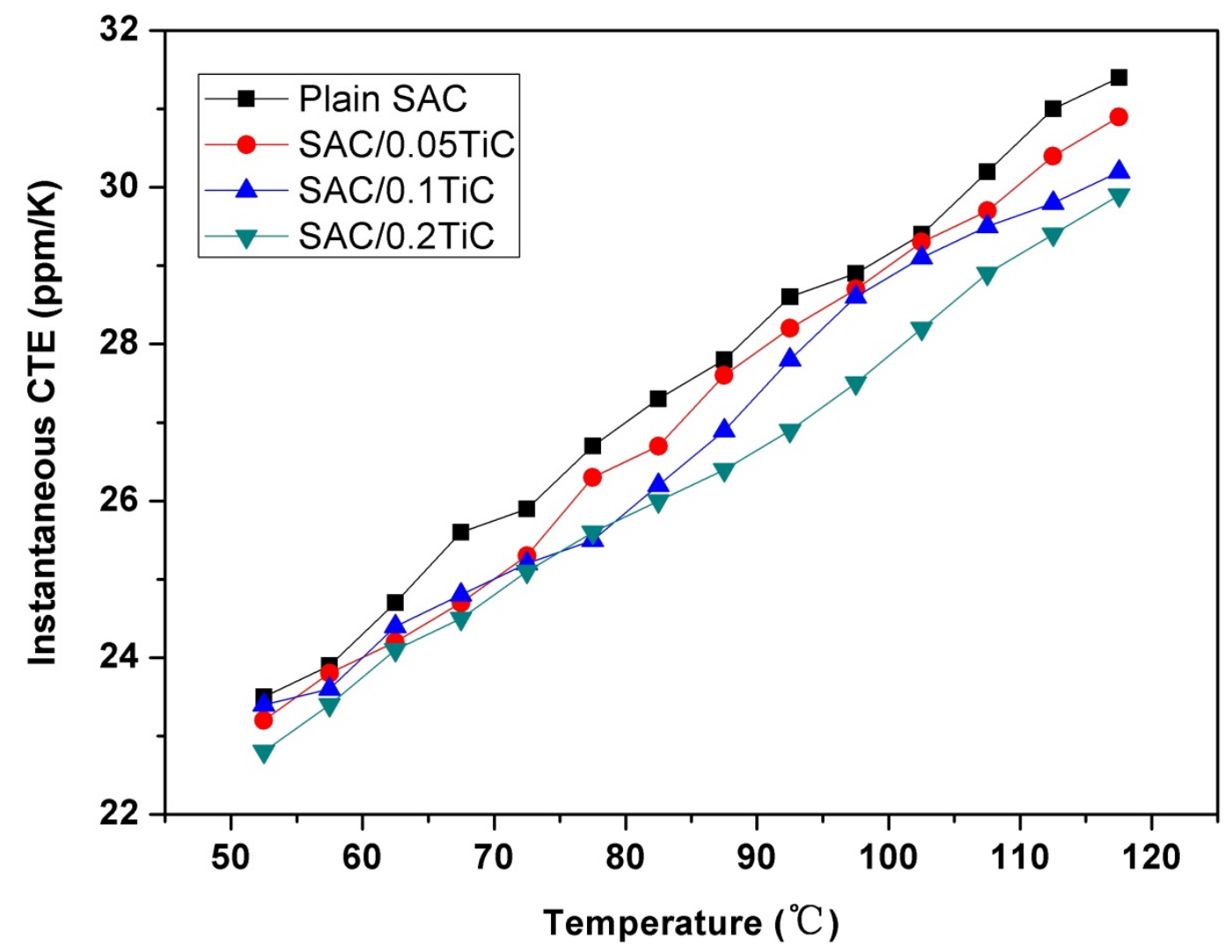

Fig. 3 Effect of temperature of instantaneous CTE for plain and composite solders 
(a)

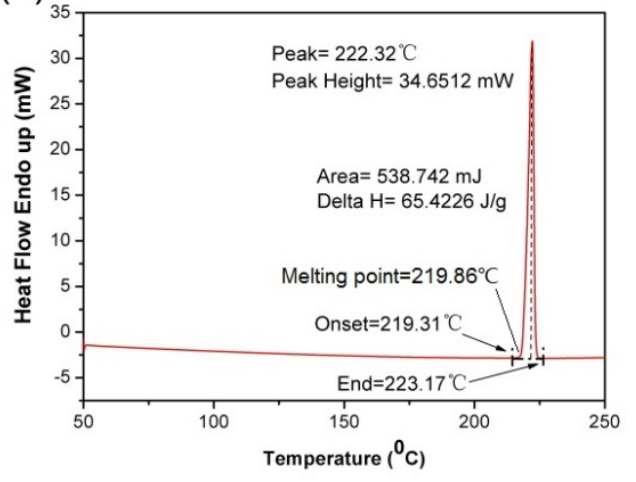

(c)

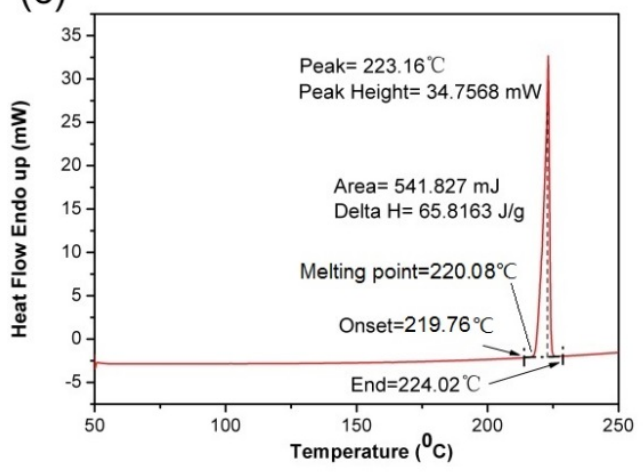

(b)

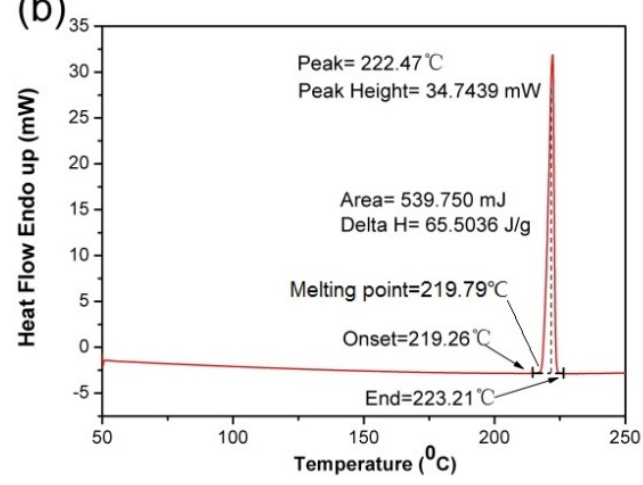

(d)

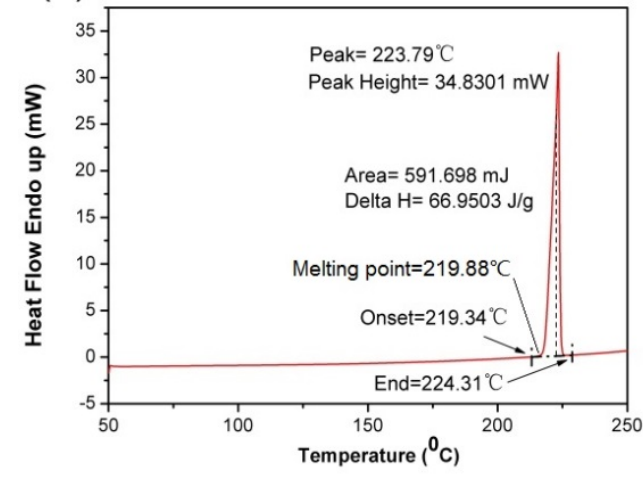

Fig. 4 DSC curves for different solders: (a) SAC; (b) SAC/0.05 TiC; (c) SAC/0.1

TiC;（d） SAC/0.2TiC 


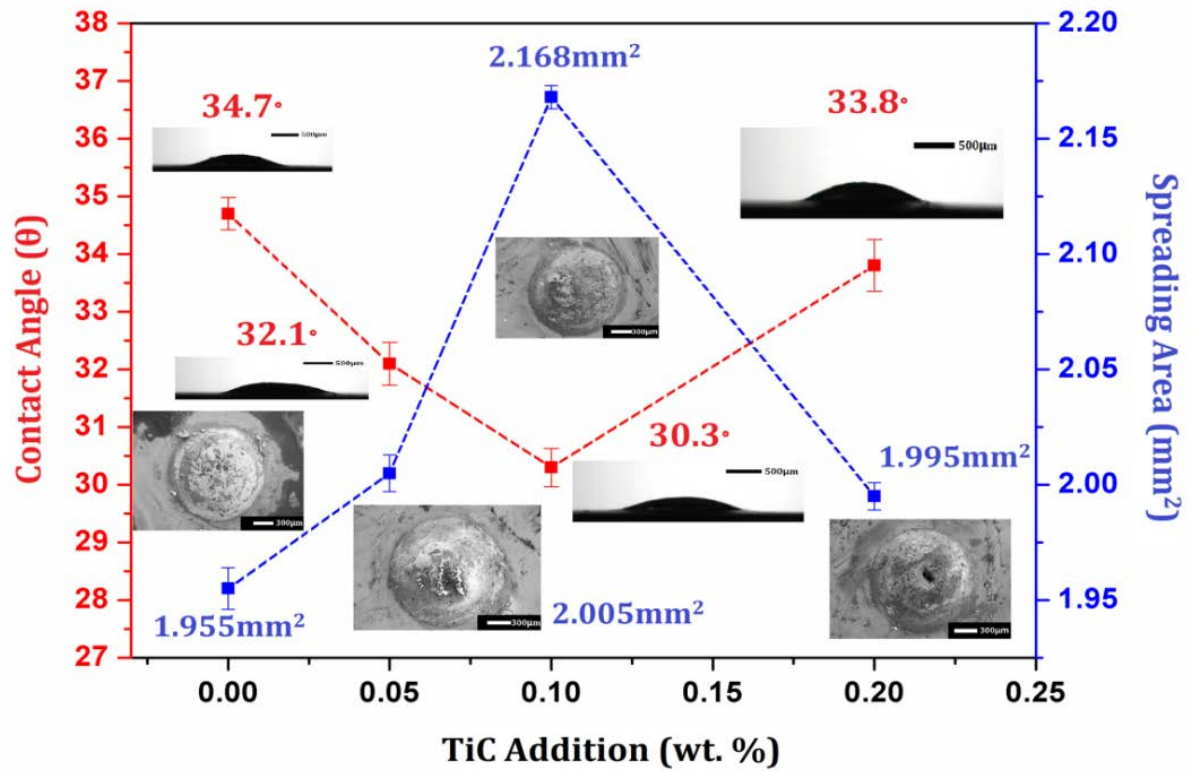

Fig.5 Effect of TiC content on contact angle and spreading area of SAC alloys 

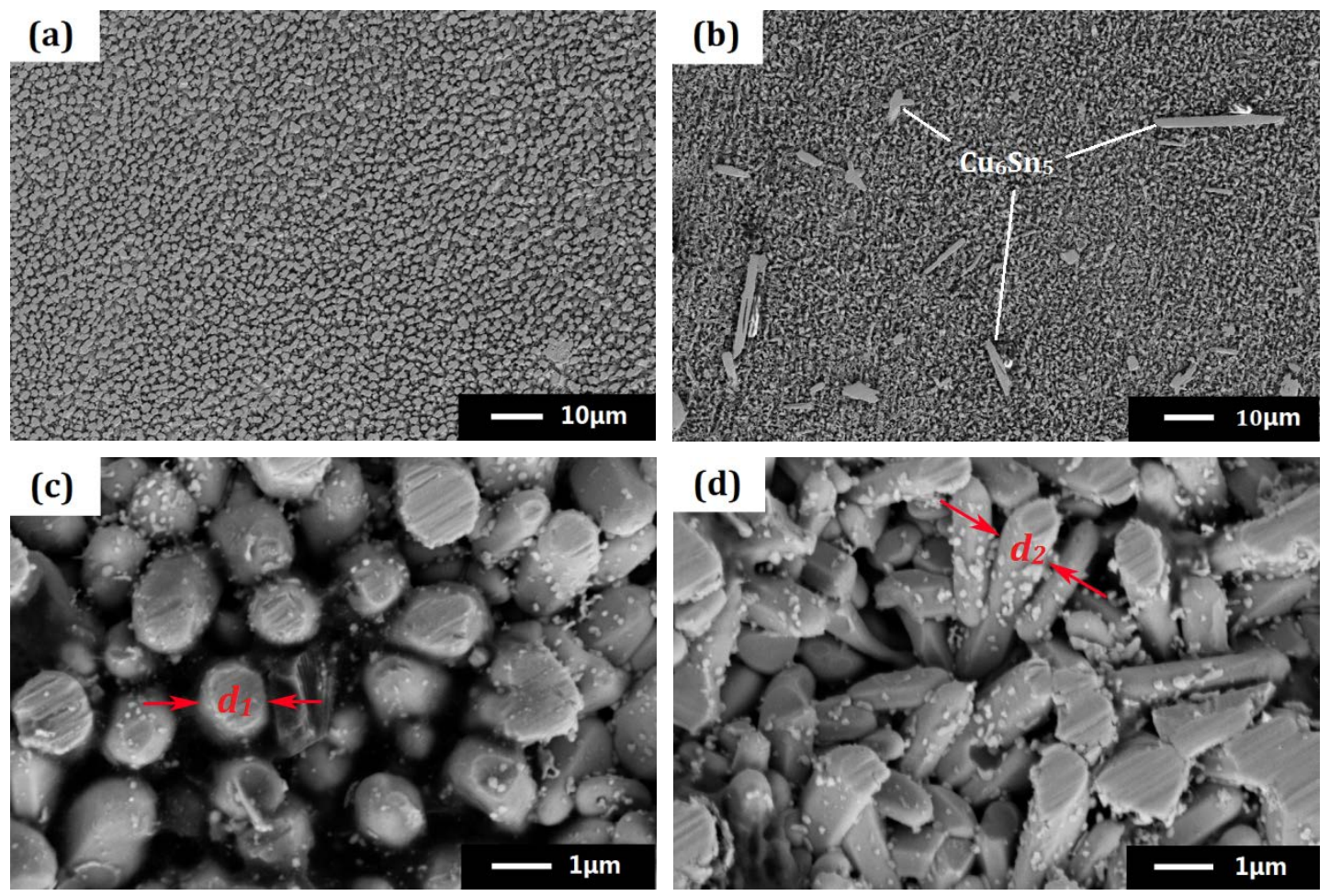

Fig.6 Typical top-view SEM images of interfacial IMCs: (a) and (c) SAC; (b) and (d) $\mathrm{SAC} / 0.2 \mathrm{TiC}$ 


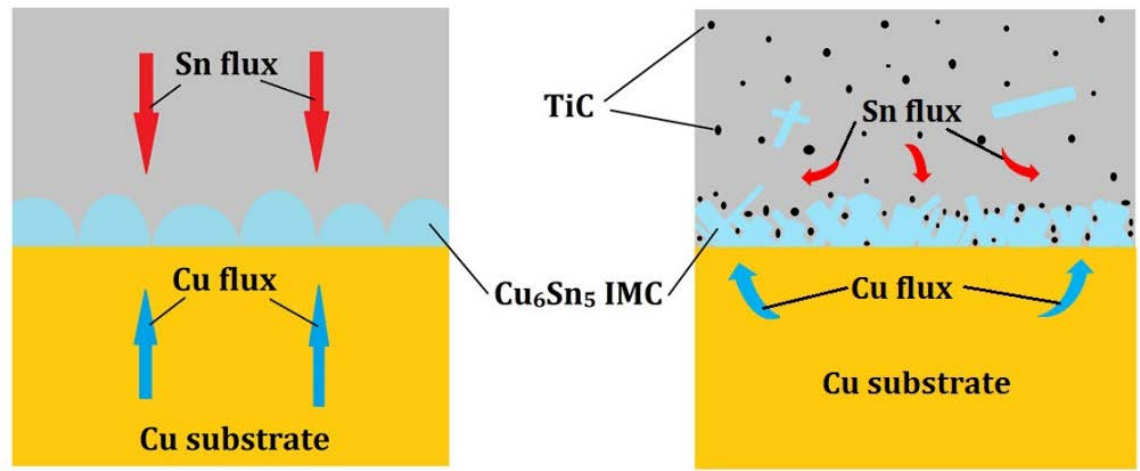

(a) $\mathrm{SAC} / \mathrm{Cu}$

(b) $\mathrm{SAC} / \mathrm{TiC} / \mathrm{Cu}$

Fig.7 Schematic of $\mathrm{Cu}$ and Sn fluxes at interface of SAC/Cu (a) and SAC-TiC/Cu (b) 


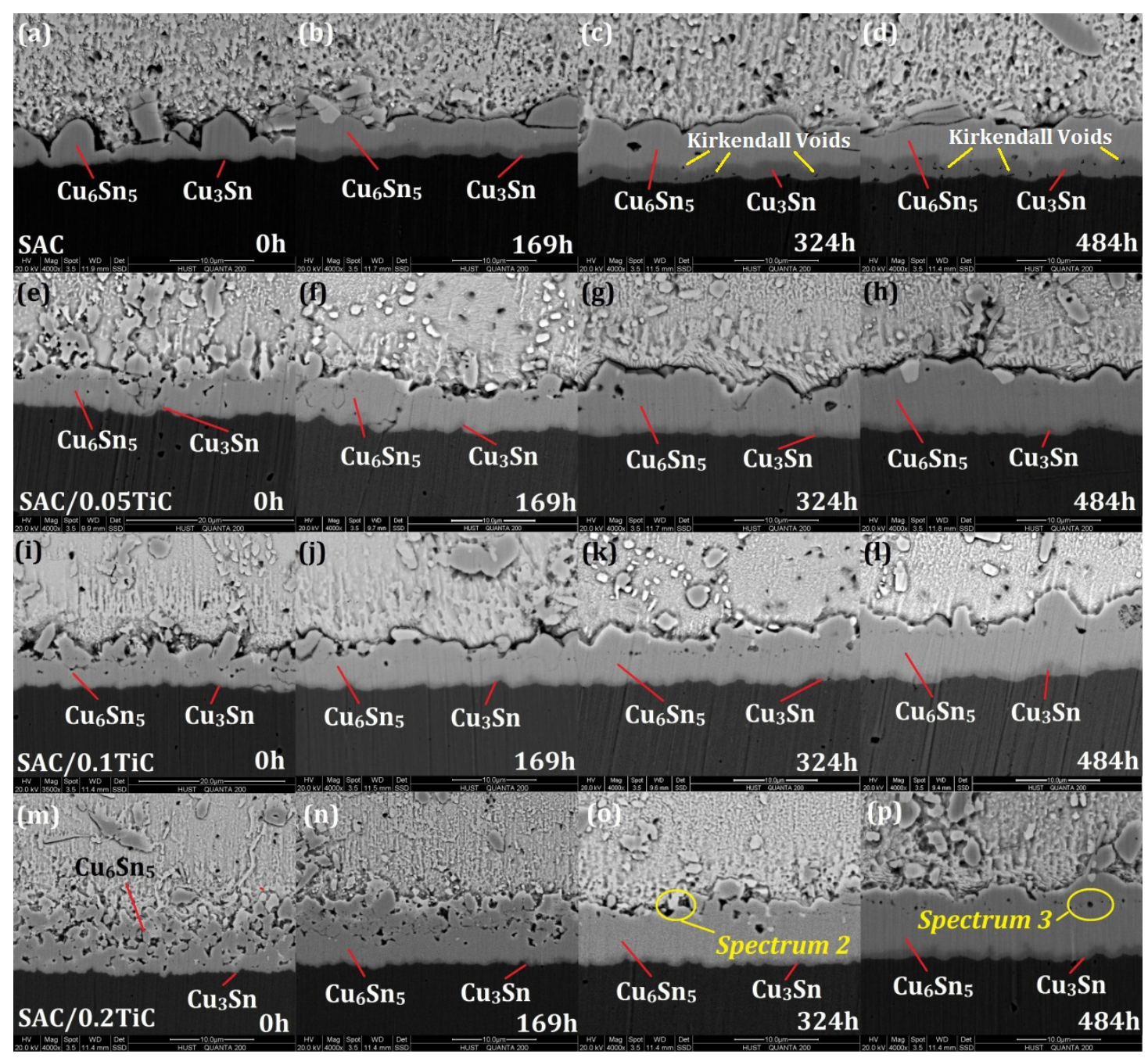

Fig.8 Morphology of interfacial IMCs before and after thermal ageing: (a)-(d) SAC;

(e)-(h) SAC/0.05TiC; (i)-(l) SAC/0.1TiC; (m)-(p) SAC/0.2TiC 


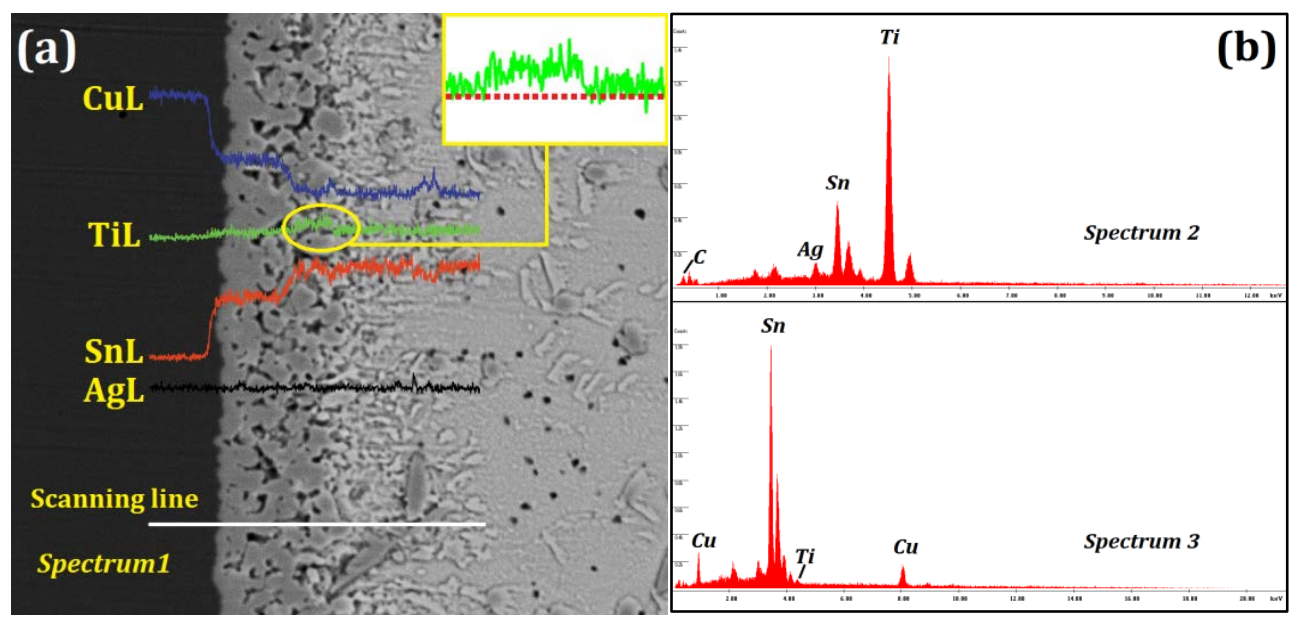

Fig.9 (a) EDS results for interfacial IMC of SAC/0.2TiC before ageing; (b) selected locations in Fig. 8 (o) and (p). 

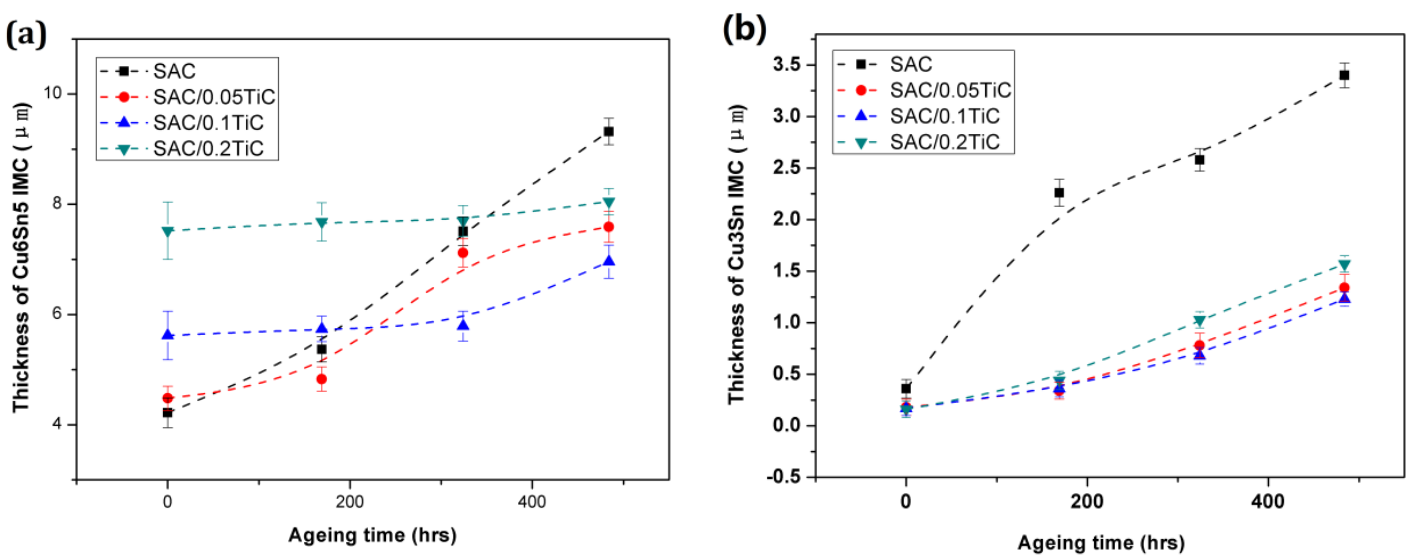

Fig.10 Evolution of thickness of interfacial IMCs with ageing time: (a) $\mathrm{Cu}_{6} \mathrm{Sn}_{5}$; (b)

\section{$\mathrm{Cu}_{3} \mathrm{Sn}$}



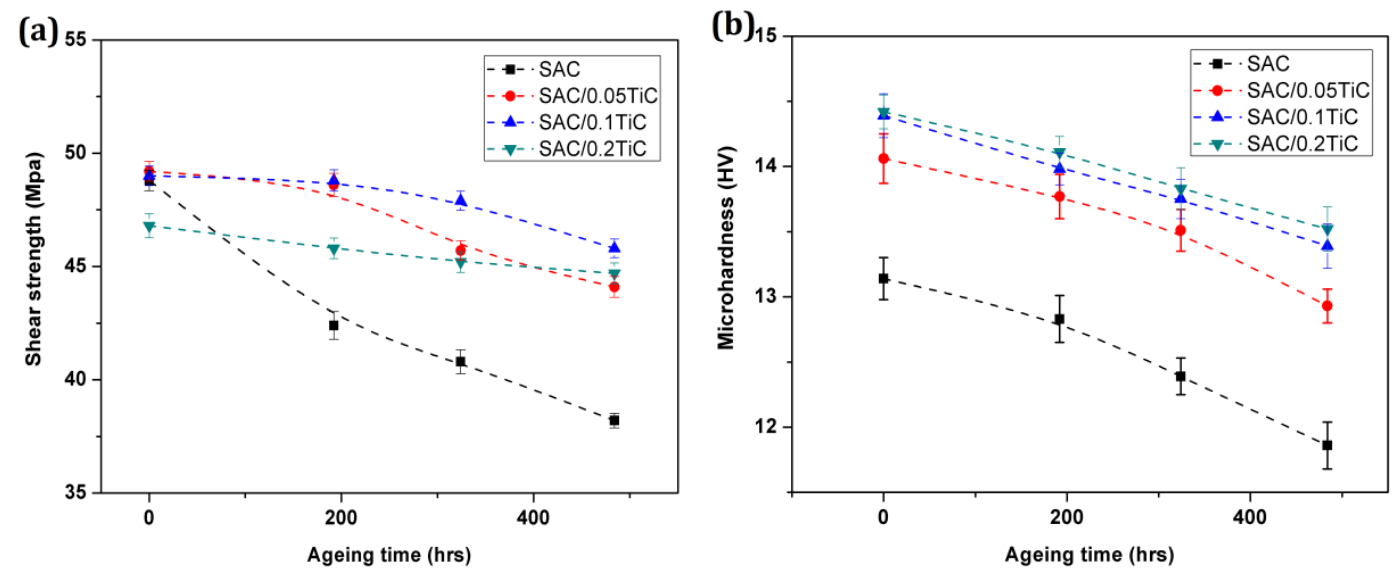

Fig.11 Effect of ageing time on shear strength (a) and microhardness (b) of solder joints 

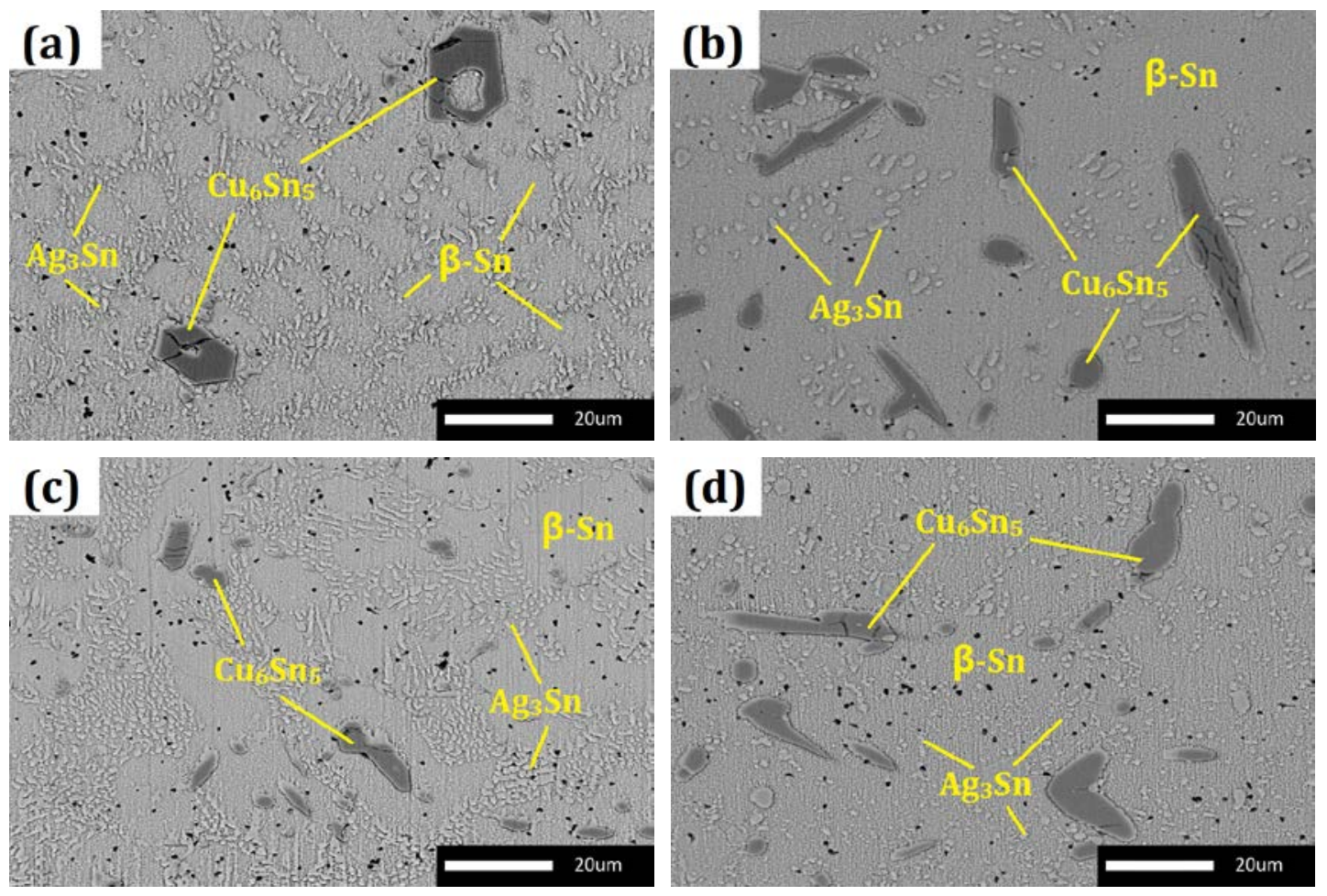

Fig.12 Typical microstructures of SAC-0 h (a), SAC-484 h (b), SAC/0.2TiC-0 h (c) and SAC/0.2TiC-484 h (d) 
Table 1 Melting parameters of different solder alloys (in ${ }^{\circ} \mathrm{C}$ )

\begin{tabular}{ccccc}
\hline & SAC & SAC/0.05TiC & SAC/0.1TiC & SAC/0.2TiC \\
Onset melting T & 219.31 & 219.26 & 219.76 & 219.34 \\
End melting T & 223.17 & 223.21 & 224.02 & 224.31 \\
Melting range & 3.86 & 3.95 & 4.26 & 4.97 \\
\hline
\end{tabular}

